\title{
Examining Dehydration and Hypoxic Stress in Wheat Plants Using a Porous Tube Plant Nutrient Delivery System Developed for Microgravity
}

\author{
T. W. Dreschel \\ NASA, Kennedy Space Center \\ C. R. Hall and T. E. Foster \\ Dynamac Corporation, Kennedy Space Center
}

\author{
M. Salganic, L. Warren, and M. Corbett \\ Spaceflight and Life Sciences Training Program, Kennedy Space Center
}

Copyright (C) 2005 SAE International

\section{ABSTRACT}

The Porous Tube Plant Nutrient Delivery System (PTPNDS) was designed for NASA to grow plants in microgravity of space. The system utilizes a controlled fluid loop to supply nutrients and water to plant roots growing on a ceramic surface moistened by capillary action. A PTPNDS test bed was developed and utilizing remote sensing systems, spectral analyses procedures, gas-exchange, and fluorescence measurements, we examined differences in plant water status for wheat plants (Triticum aestivum, cv. Perigee) grown in a modified growth chamber during the summers of 2003 and 2004. Some differences in plant performance were detectable in the gas-exchange and fluorescence measurements. For instance, in both years the plants grown with the most available water had the lowest rates of photosynthesis and exhibited higher proportions of non-photochemical quenching particularly under low light levels. In addition, small differences in mean leaf water content between treatments were detected using spectral reflectance analyses.

\section{INTRODUCTION}

Many types of plant research can benefit from development of technologies to precisely control, alter, and monitor plant growth and physiological processes. The ideal test plant growth system would allow for control of the spectral quality and intensity of the light environment, the water and nutrient contact with the root system, the temperature and humidity of the growth area, and the concentration of gases in the atmosphere. Today's high quality plant growth chambers can be used to address the atmospheric gas, temperature, and humidity concerns. Advances in lighting technology such as light-pipe, LED and other innovative lamps as light sources are addressing issues associated with control of the photosynthetically active radiation environment. Creation of a reliable simple system for controlling the flow of water and chemicals directiy available to plant roots provides tremendous opportunities for plant research in areas such as remote sensing of plant stress, toxicology testing, tissue culture of plants, and plant physiology. By accurately controlling the plants growth environment to minimize variance resulting from environmental responses we can begin to more accurately define treatment effects and minimum detectable differences in physiological characteristics as they relate to sampling strategies and procedures.

The Porous Tube Plant Nutrient Delivery System (PTPNDS) is a system designed to control water and nutrient availability to plants; specifically developed to overcome many of the challenges in providing water and mineral nutrients to the roots of plants in microgravity (Dreschel 1990) and in certain ground systems (Dreschel and Brown 1993). The PTPNDS (Dreschel 1990) was originally designed for NASA for growing plants in the microgravity of space. In microgravity, plant rhizospheres tend to become anoxic because gravity-mediated convection is non-existent. To avoid these problems, the delivery of water and dissolved nutrients to roots grown in microgravity must be done in a precise fashion. The PTPNDS utilizes a controlled fluid loop to supply nutrients and water to plant roots growing on a ceramic surface moistened by capillary action. See Berry et al. (1992) for a detailed description of the PTPNDS. Preliminary studies with the 
PTPNDS have centered around testing the system with various crop plants (Dreschel, et al. 1992; Dreschel, et al. 1988); (Bubenheim et al. 1987), developing hydraulic pressure control systems for laboratory-scale crop tests (Dreschel and Brown 1993; Dreschel et al. 2004), measuring the effects of hydraulic pressure, pore size, and root zone volume on plant growth (Dreschel et al. 1989a; Dreschel et al. 1989b; Peterson et al. 1989; and Berry et al. 1992)

developing physical and mathematical models to describe the operation of the system (Tsao et al. 1996; Tsao et al. 1992) and utilizing the system to grow crop plants in the confines of ground-based spaceflight plant growth unit such as the one patterned after the Russian SVET hardware (Chetirkin et al. 1994). The PTPNDS has also been used as a research tool to evaluate the response of plants to varying degrees of water and nutrient stress (Dreschel and Sager 1989; Dreschel et al. 1989b and Dreschel et al. 2004) and to investigate the hydrotropic response of plant roots to moisture gradients (Takahashi et al. 1992).

In this study, we use the PTPNDS to investigate the potential for using an infrared gas exchange system, a fluorometer and a hyperspectral spectrometer to detect small differences in the water status of plants. The determination of biomass, water status, photosynthetic rates, chemical concentrations, and biophysical features of vegetation are recognized as important objectives for remote sensing in agriculture, terrestrial ecology, and earth system science. Water-stressed plants are expected to exhibit a decrease in photosynthesis and conductance while experiencing an increase in fluorescence at high light intensities and previous studies have shown that remote sensing techniques were useful for characterizing water status of scrub oak leaves (Bostater et al. 1994)

\section{MATERIALS AND METHODS}

The Porous Tube Plant Nutrient Delivery Systems (PTPNDS), consists of eight covered porous tubes (Figure 1), $75 \mathrm{~cm}$ long with a $2 \mathrm{~cm}$ O.D. mounted on a laboratory cart, each connected to a manifold from a standpipe at one end, and a peristaltic pump at the other end. A submersible pump carries nutrient solution from a 40-liter reservoir to a standpipe providing the solution to the manifold. Root water potential at the surface of the porous tubes is controlled by adjusting the height of the standpipe relative to the height of the porous tubes. Seeds are planted on the surface of the porous tube within the "space for seeds" (Figure 1) and covered with a small section of laboratory wipe (Kimwipe ${ }^{\mathrm{tm}}$ ) for germination. Following germination, the roots surround the porous tube and receive water and nutrients directly from the surface of the tube by capillary action.

During the summers of 2003 and 2004, wheat seeds (Triticum aestivum, cr. Perigee) were planted on the PTPNDS system (June 6, 2003 and May 26, 2004). The seeds were wrapped in a large, damp laboratory wipe, placed in a plastic bag and refrigerated for 48 hours.

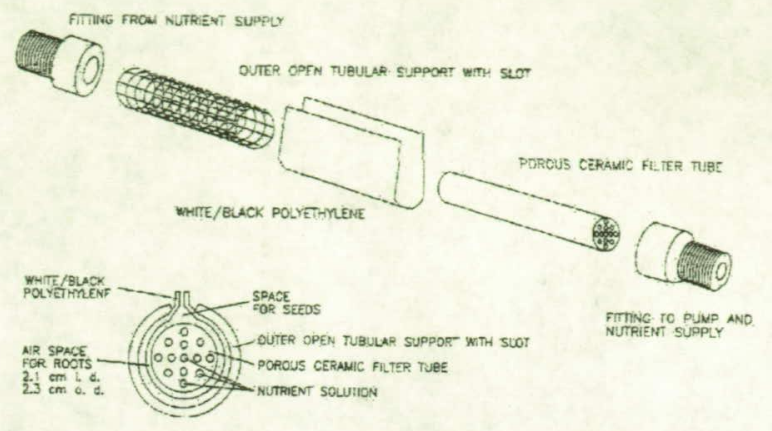

Figure 1. A Diagram of the Porous Tube Component of the PTPNDS.

Thirty seeds were then planted on the surface of each porous tube within the "space for seeds" and covered with a small strip of laboratory wipe to maintain the seeds in a moist environment until germination. Nutrient solution was created by combining 1.0 gram of 5-11-26 hydroponic mix and 0.6 gram of Calcium Nitrate (Southern Agricultural Products ${ }^{\mathrm{tm}}$ ) to each liter of water. This was mixed directly in the 40-liter reservoir. Following germination, the PTPNDS standpipes were adjusted to the appropriate pressures to provide the root water potential treatments. In 2003 standpipes were set to $-40 \mathrm{~cm}(-3.92 \mathrm{kPa}),-20 \mathrm{~cm}(-1.96 \mathrm{kPa})$ and $-1 \mathrm{~cm}$ $(-0.098 \mathrm{kPa})$. The difference in pressure between the treatments was decreased in $2004 ;-20 \mathrm{~cm}(-1.96 \mathrm{kPa})$, $-10 \mathrm{~cm}(-0.98 \mathrm{kPa})$, and $-1 \mathrm{~cm}(-0.098 \mathrm{kPa})$. Following germination, plant height was measured for each plant on a regular basis.

During the 2003 experiment, the plants on the -0.098 $\mathrm{KPa}$ treatment displayed signs of yellowing and stunted growth by week two (Figure 2, foreground). In an attempt to alleviate this, the standpipe was lowered to -5 $\mathrm{cm}(-0.49 \mathrm{kPa})$ and left there for the remainder of the study.

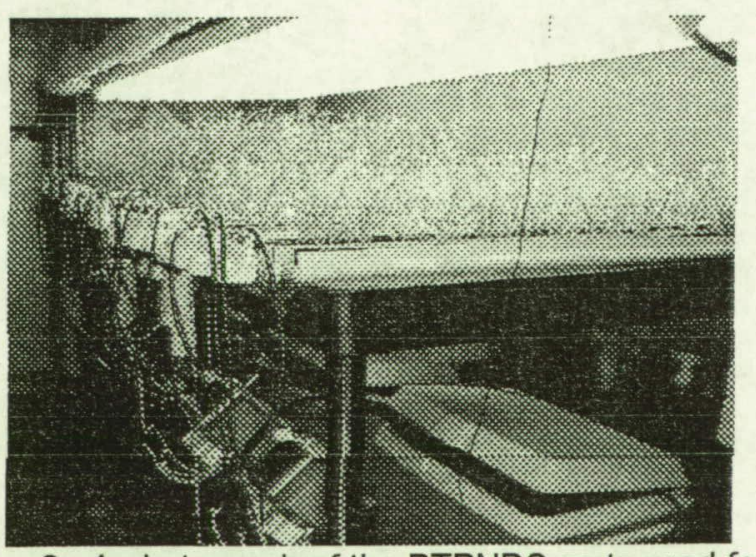

Figure 2. A photograph of the PTPNDS carts used for the 2003 study. Plants in the foreground were originally grown at water pressures of $-0.098 \mathrm{kPa}$ but due to poor growth were changed to a pressure of $-0.49 \mathrm{kPa}$. 
Daily or weekly measurements consisted of chamber temperature and humidity, plant canopy temperature, reservoir level and volume of water added, solution temperature, $\mathrm{pH}$, and conductivity for each reservoir, canopy light level, and plant height.

In addition, the following were measured at least once during the study: percent germination, photosynthesis, stomatal conductance and fluorescence, fresh weight, dry weight, percent moisture and spectral reflectance.

Physiological parameters were measured with a LiCor 6400 Portable Photosynthesis System (LiCor ${ }^{\mathrm{tm}}$; Lincoln, $\mathrm{NE}$ ) on fiag leaves of plants from each treatment. Measurements of photosynthesis, stomatal conductance, and fluorescence were taken on three plants from each cart over a two day period between the 25 and 27 DAP. Leaves were dark adapted for 20 minutes using the LiCor 6400 with the leaf chamber fluorometer attachment. Fluorescence and gasexchange measurements were made on the darkadapted leaf. After dark-adapted measurements were taken, fluorescence light curves were made on each leaf. Measurements were taken at eight light levels $(1200,1000,800,600,300,100,50$, and 0 umols photons

$\mathrm{m}^{-2} \mathrm{~s}^{-1}$ ). In 2004, measurements were also take at 1600 $\mu$ mols photons $\mathrm{m}^{-2} \mathrm{~s}^{-1}$. Data was graphed and compared for trends between the treatments.

Spectral data were collected using an Analytical Spectral Devices (ASD) Fieldspec Pro spectrograph (ASD 1999). Downweliing radiance (as digital number) was estimated using a Spectralon white reflectance panel. Upwelling radiance was measured as the average of 30 spectral samples of each leaf.

Reflectance was calculated as the ratio of the upwelling to the downwelling values. All spectral measurements were made using a tungsten light source set at a constant output level with a rheostat. All angles of measurement, illumination and distances between target leaves, light source and ASD optical probe were held constant to minimize bi-directional influences. For each treatment, flag leaves from selected plants were used in the spectral measurements. Leaf spectral reflectance was measured immediately after fresh weights of the plants were determined (Ohaus ${ }^{\mathrm{tm}}$ Analytical Plus Balance; $\pm 0.001 \mathrm{~g}$ ). The plants were then dried at $70^{\circ} \mathrm{C}$ for 72 hours and reweighed to determine the plant dry weight.

Data collected with the ASD spectrograph were subsampled at $5 \mathrm{~nm}$ intervals to reduce issues associated with correlations between adjacent spectral bands (Demetriades-Shah et al. 1990). Analyses focused on data that demonstrated significant differences in leaf percent moisture for the three applied water potentials. A simple correlation analyses was run between the spectral reflectance data and the percent moisture to define first order relationships between reflectance values and leaf moisture. To assess possible relationships between leaf percent moisture and spectral curvature or inflection a three band inflection ratio (Grew 1980; Bostater et al. 1994) was computed. Spectral smoothing was utilized to reduce influences of noise and maximize the signal (Demetriades-Shah et al. 1990). Inflection estimates were calculated according to methods described in Dreschel et al. (2004).

Correlograms were generated to identify areas of strong correlation between the inflection estimator and leaf percent moisture. Analysis of variance was used to test for significant differences between inflection values in the regions of highest correlation associated with the three levels of root water potential. The Bonferroni pairwise mean comparison test was used to test between individual treatment differences. Analyses and data processing were conducted with Systat 9 (SPSS 1999).

\section{RESULTS}

In 2003 the height growth was similar for the plants at the two most negative water potentials $(-3.92 \mathrm{kPa}$ and $1.96 \mathrm{kPa}$ ), whereas in 2004 height growth was similar between all three treatments (Figure 3 ). During both years, height growth peaked at approximately $25 \mathrm{~cm}$.

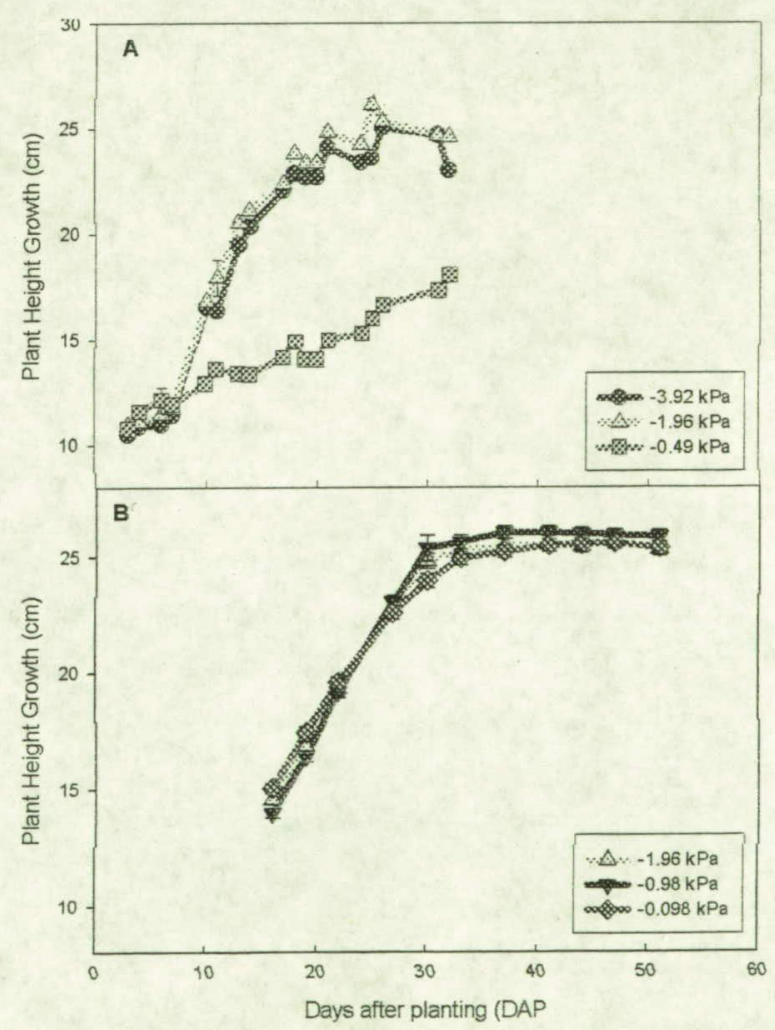

Figure 3. Plant heights over the course of the A) 2003 growing period and B) 2004 growing period.

The percent leaf moisture of plants followed the same general trend in both years (Figure 4). The plants with the most available water $(-0.49 \mathrm{kPa}, 2003 ;-0.098 \mathrm{kPa}$ 2004) had the highest percent leaf moisture. In 2003 , the two treatments with the least available water $(-3.92$ $\mathrm{kPa}$ and $-1.96 \mathrm{kPa}$ ) were similar in percent moisture 
(Figure 4A). However, in 2004 the $-1.96 \mathrm{kPa}$ treatment had lower percent moisture than the $-0.98 \mathrm{kPa}$ treatment.
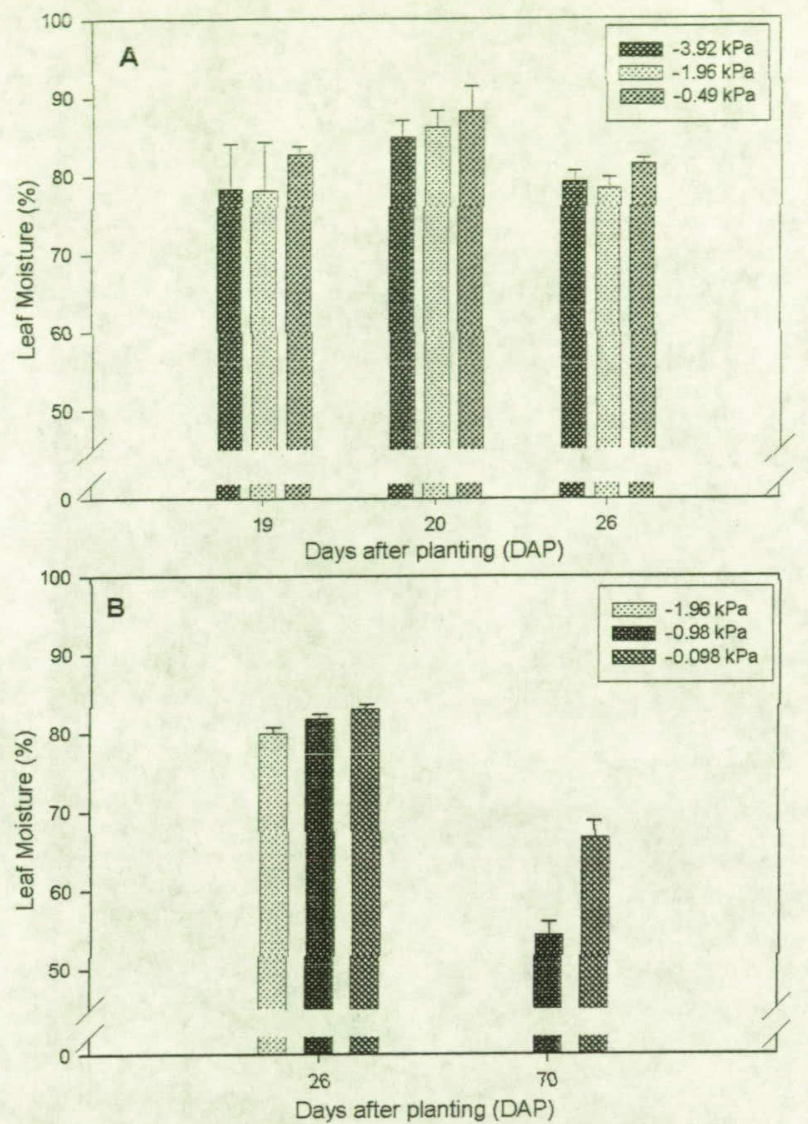

Figure 4. Percent leaf moisture for the different water treatsments in A)2003 and B) 2004.

No clear trend in stomatal conductance was seen between the two years. However, trends were observed in photosynthesis and non-photochemical for both years (Figures 5 and 6 respectively). The plants grown with the most available water had the lowest rates of photosynthesis and the highest rates of nonphotochemical quenching at low light levels. Maximum photosynthesis was achieved at close to $20 \mu$ mols $\mathrm{CO}_{2}$ $\mathrm{m}^{-2} \mathrm{~s}^{-1}$. These low rates of non-photochemical quenching were exhibited at all light leveis for the -0.49 $\mathrm{kPa}$ grown plants during 2003 , but were exhibited only at the low light levels during 2004.

Spectral reflectance of plant leaves grown with the most available water displayed increases in reflectance in the 400 to $680 \mathrm{~nm}$ visible region of the spectrum. In the infrared region there were no statistical differences in the percent reflectance values, within treatment variance was high (Figure 7).

Percent leaf moisture was correlated with inflection for the near infrared spectral region (Figure 8). Significant negative correlation was detected at the $870 \mathrm{~nm}$ wavelength $(r=0.681 ; p=0.02)$.

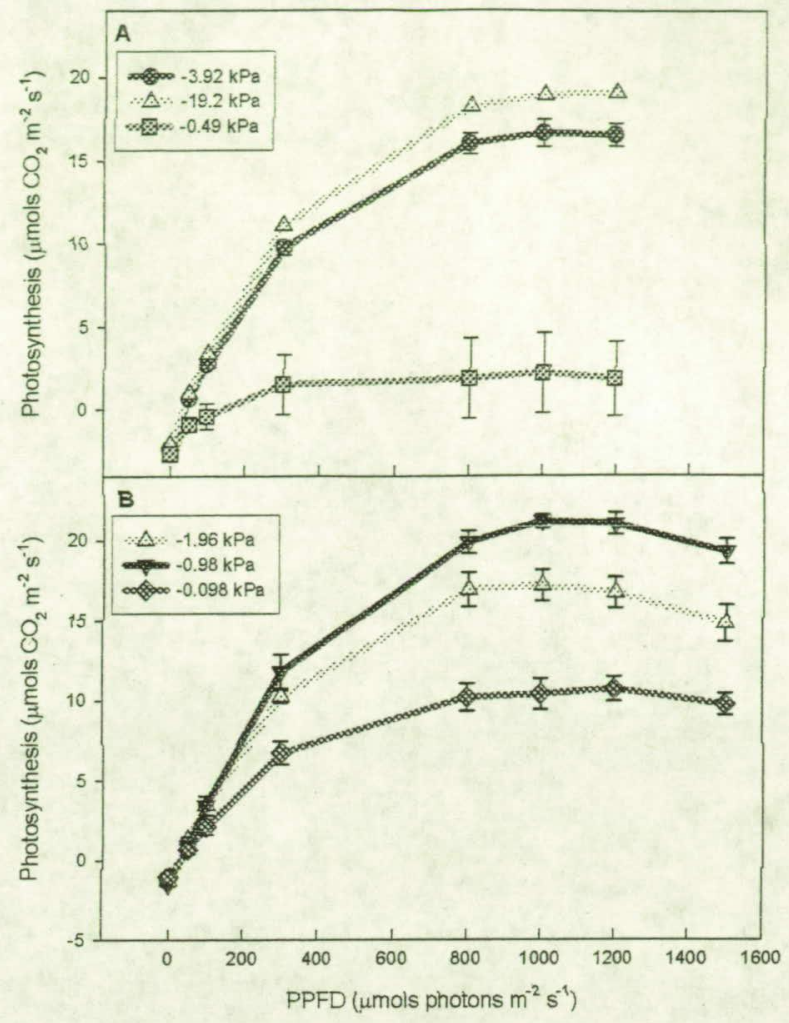

Figure 5. Photosynthesis for the different water treatments in A) 2003 and B) 2004.

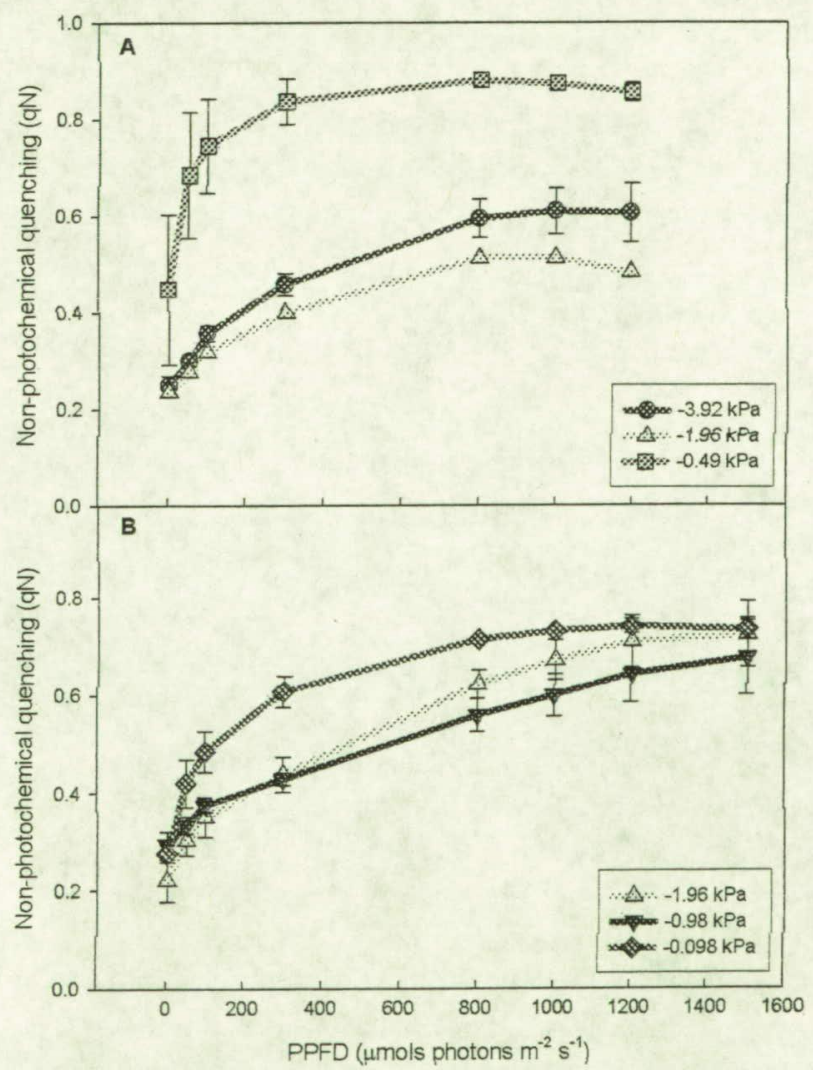

Figure 6. Non-photochemical quenching for the three treatments in A) 2003 and B) 2004. 


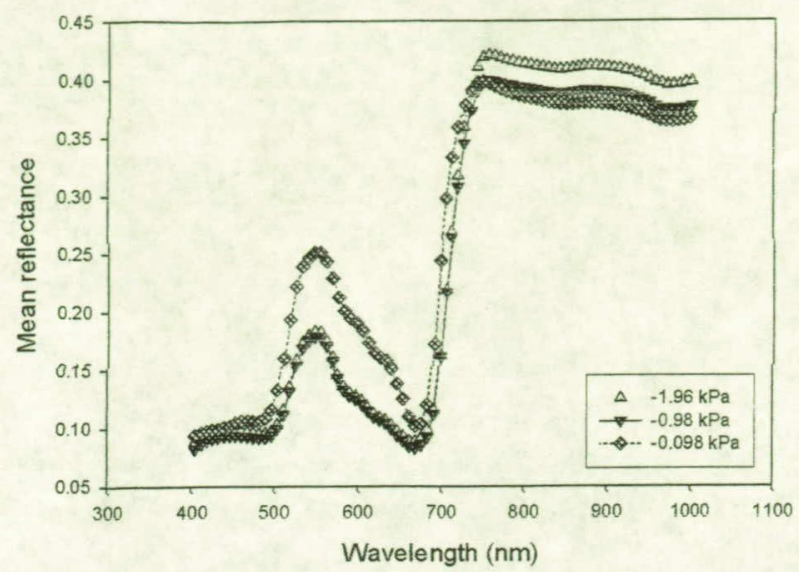

Figure 7: Spectral reflectance for each treatment from data collected in 2004.

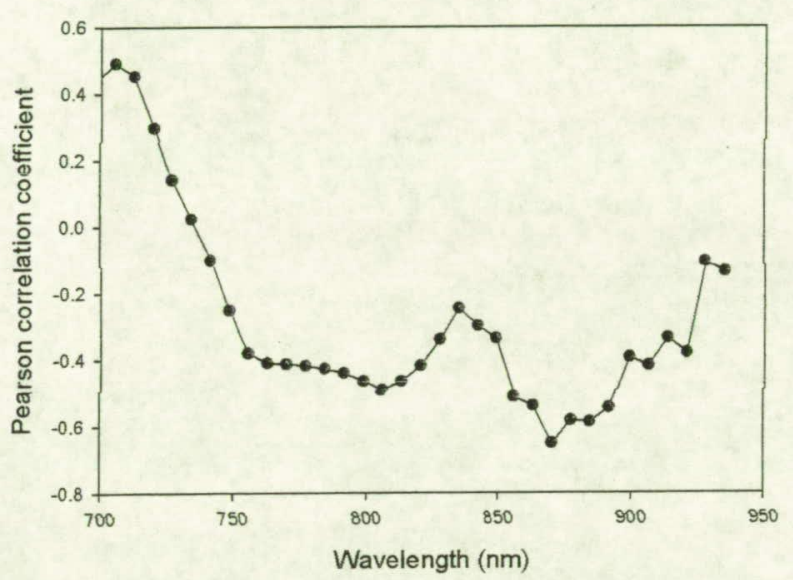

Figure 8: Correlation between percent moisture and inflection estimate for plants grown in 2004.

Treatment differences were present (ANOVA; $p=0.001$ ) for the 2004 inflection data. Significant differences between the treatment with the most available water $(-0.098 \mathrm{kPa})$ and the other two treatments $(-0.98 \mathrm{kPa}$ and $-0.96 \mathrm{kPa}$ ) were found for the inflection estimates at $870 \mathrm{~nm}$ wavelength (Bonferroni pairwise; $p=0.001$ ). However, in 2003 this trend was not observed because of increased variability within treatment measurements (data not shown).

\section{CONCLUSION}

The amount of applied water potential that the roots were exposed to was small when compared to commonly accepted field capacity values (soil at near water saturation) of around $-1 / 3$ atmosphere. Even the largest of our applied water potentials was only about one-tenth that of an accepted value for field capacity. Yet these differences were detectable using spectral analysis and gas-exchange measures.

Small differences in leaf water content were detectable in several physiological parameters, in a previous study, Dreschel et al. (1990) found that wheat plants grown to maturity under three different water potentials demonstrated differences in yield relative to the water potential. This phenomenon was also demonstrated for other physiological features in previous studies (Dreschel et al. 2004). For example, with a decrease in applied water potential (becoming more negative), the resultant yield and photosynthetic rates were reduced. Therefore it was expected that the treatment with the most available water would exhibit superior growth compared to the other two applied water potentials. However, this was not the case in either 2003 or 2004.

Under water-stressed conditions, plants are expected to exhibit a decrease in photosynthesis and conductance while experiencing an increase in fluorescence at higher light intensities. Berry et al. (1992) found that wheat plants grown under various applied water potentials on the PTPNDS demonstrated differences in net carbon dioxide uptake and water use efficiency. Lu and Zhang (1998) found that a cultivar of wheat (Triticum aestivium L. CV. Shannong 229) when exposed to high light it was only the more severely water-stressed plants that exhibited a difference in measures of fluorescence.

In the current study, plants with the most available water showed the greatest signs of stress. In 2003, these plants $(-0.49 \mathrm{kPa})$ appeared to be under water-logged conditions early in their life cycle and until the amount of leaf transpiration was sufficient to overcome this condition, the plant roots were oxygen stressed. When the leaf transpiration rates were sufficient, the growth rate of the plants accelerated and matched or exceeded the growth rate of the plants grown with the other two applied water potentials. In 2004, the plants grown with the most available water $(-0.098 \mathrm{kPa})$ did not exhibit stunted growth, but they did exhibit other characteristics of stressed plants that were also seen in the 2003 data. These plants had lower rates of photosynthesis and their non-photochemical quenching was greater than that of the treatments with less available water.

Absolute differences in the non-photochemical quenching observed between the two years were most likely due to differences in the lighting apparatus. As seen in the 2004 data, all plants were stressed under high light conditions. This same type of stress was not seen in 2003 when the plants were grown under more intense and also more variable lighting conditions. This indicates that the other water potentials, at which the wheat plants were grown, were not extreme enough to cause water stress responses that could be detected with physiological measures.

Differences were not only seen in the physiological parameters but also in spectral reflectance data analyses. Two regions of the infrared reflectance spectra, the near- $(700-1300 \mathrm{~nm})$ and middle- (1300$3000 \mathrm{~nm}$ ), have been identified as being useful for the detection of vegetation water stress or water content (Tucker 1980, Ripple 1986). Organic bonds found in 
foliar mass exhibit vibrational stretching modes that absorb radiation in these regions of the spectrum. Pure water absorption bands occur at around $760,970,1450$ 1940 , and $2950 \mathrm{~nm}$ in response to the $\mathrm{OH}$ bond (Grant 1987). Bostater et al. (1994) found that changes in the curvature or inflection of the reflectance signature in the $970 \mathrm{~nm}$ region was highly correlated with water potential and percent moisture of scrub oak leaves.

Successful algorithm development for feature characterization requires development of a quantitative understanding of complex interactions that occur between photons and the numerous absorbing and scattering components of targets (Bostater et al. 1994, Asner 1998). For plants, these wavelength dependent interactions involve tissue optical properties, canopy biophysical attributes, bottom reflectance (soil and litter), and illumination characteristics.

In this study, changes in the shape of the spectral curve between 820 and $940 \mathrm{~nm}$ displayed significant correlations with percent moisture in the super dwarf wheat plant leaves. An especially encouraging result was the ability to identify, with derivative analyses of the raw spectral data (Figure 8 ), the small change in mean leaf water content of $3 \%$ that occurred between treatments. This feature could not be detected utilizing raw reflectance data values (Figure 7) that displayed no significant correlations with percent moisture in leaves.

In future studies we will attempt to better characterize the hypoxic environment created and further refine our ability to measure these stresses. The use of plants with inserted reporter genes such as those using the green fluorescent protein gene associated with genes that respond to hypoxic stress and to dehydration stress would allow us to better examine the response of the plants to manipulation within this nutrient delivery system.

\section{ACKNOWLEDGMENTS}

This work was conducted under NASA contract NAS1012180 and the Life Sciences Services Contract at Kennedy Space Center. Technical support was provided by Robin Shaw through The NASA Summer High School Apprenticeship Research Program and Lesley Warren through the NASA Spaceflight and Life Sciences Training Program. Special thanks to Dr William Knott III, Senior Scientist at Kennedy Space Center, for his support and continued encouragement.

\section{REFERENCES}

Analytical Spectral Devices (ASD). 1999. Fieldspec Pro spectrograph Users Manual, Analytical Spectral Devices Inc., Boulder, CO.
Asner, G. P. 1998. Biophysical and biochemical sources of variability in canopy reflectance. Remote Sens. Environ. 64:234-253.

Berry, W. L., G. Goldstein, T. W. Dreschel, R. M. Wheeler, J. C. Sager, and W. M. Knott. 1992. Water Relations, Gas Exchange, and Nutrient Response to a Long Term Constant Water Deficit. Soil Science 153(6): 442-451.

Bostater, C. R., Hall, C. R., Vieglais, D., Rebmann, J., Provancha, M. (1994), Temporal measurements of high resolution spectral signatures of plants and relationships indicating water status, in Proceedings of the International Symposium on Spectral Sensing Research (R.B. Gomez, Ed.), 10-15 July, Volume I, San Diego, CA, pp. 387-402.

Bubenheim, D. L., T. W. Dreschel, and C. A. Mitchell. 1987. Comparison of Plant Growth in a Tubular Membrane Hydroponic System with that in Conventional Hydroponic Culture. HortScience 22(5):75 (abstr).

Chetirkin, P. V., T. W. Dreschel, J. C. Sager, and Y. A. Berkovitch. 1994. SVET-M (CBET-M): Evaluation of a Ground-Based Version of a Russian Plant Growth Chamber. ASGSB Bulletin 8(1):57 (abstr.).

Demetriades-Shah, T. H., M.D. Steven, and J. A. Clark. 1990. High Resolution Derivative Spectra in Remote Sensing. Remote Sens. Environ. 33:55-64.

Dreschel, T. W., J. C. Sager, and R. M. Wheeler. 1988. Status of Porous Tube Plant Growth Unit Research. Mimeogr. Paper \#88-4524 presented to the American Society of Agricultural Engineers.

Dreschel, T. W. and J. C. Sager. 1989. Control of Water and Nutrients Using a Porous Tube: A Method for Growing Plants in Space. HortScience 24(6):944947.

Dreschel, T. W., J. C. Sager, and R. M. Wheeler. 1989a. Plant Growth in a Porous Tube Nutrient Delivery System: The Effects of Pressure and Pore Size on Productivity. ASGSB Bulietin 2(1):37-38 (abstr).

Dreschel, T. W., R. M. Wheeler, J. C. Sager, and W. M. Knott. 1989b. Factors Affecting Plant Growth in Membrane Nutrient Delivery. In R. D. MacElroy, ed. Controlled Ecological Life Support Systems: CELSS '89 Workshop, NASA Technical Memorandum \#102277, Ames Research Center, Moffett Field, California.

Dreschel, T. 1990. Plant Nutrient Delivery System having a Porous Tubular Member. Patent \# 4,926,585. United States Patent and Trademark Office, Washington, D.C.

Dreschel, T. W., C. S. Brown, C. R. Hinkle, J. C. Sager, R. M. Wheeler, and W. M. Knott. 1992. A Summary of 
Porous Tube Nutrient Delivery System Investigations from 1985 to 1991. NASA Technical Memorandum \# 107546, The National Aeronautics and Space

Administration, J. F. Kennedy Space Center, Fiorida.

Dreschel, T. W. and C. S. Brown. 1993. Water Conserving Plant-Growth System. NASA Tech Briefs 17(1):89-90.

Dreschel, T. W., C. R. Hall, and T. E. Foster. 2004. Demonstration of a Porous Tube Hydroponic System to Control Plant Moisture and Growth. NASA Technical Memorandum \# 2004-211533, The National Aeronautics and Space Administration, J. F. Kennedy Space Center, Florida.

Grant, L. 1987. Diffuse and specular characteristics of leaf reflectance, Remote Sens. Environ. 22:309-322.

Grew, G. 1980. Real-time test of MOCS algorithm during Superflux 1980. in. Pages 301-322 in Chesapeake Bay Plume Study, Superflux 1980. NASA Pub. 2188, Washington, D. C.

Jacquemoud, S., Verdebout, J., Schmuck, G., Andreoli, G., and Hosgood, B. 1995. Investigation of leaf biochemistry by statistics. Remote Sens. Environ. 54:180-188.

Lu, C. and J. Zhang. 1998. Effects of water stress on photosynthesis, chlorophyll fluorescence and photoinhibition in wheat plants. Aust. J. Plant Physiol 25: 883-892.

Monje, O., H.T. Wang, C. Kelly, and G.W. Stutte. 2001. Nutrient delivery system water pressures affect growth rate by changes in leaf area, not single leaf photosynthesis. SAE Technical Paper 2001-02-2277.

Peterson, T. A., D. T. Krizek, and T. W. Dreschel. 1989. Tomato Plant Growth on a CELSS Tubular Membrane Growth Unit. ASGSB Bulletin 3(1):93 (abstr).

Porterfield, D. M. 1996. Characterization of Physiological Changes in Roots Grown in Spaceflight Conditions: A Comparison of Nutrient Delivery Technologies. Dissertation, Department of Plant Pathology and Crop Physiology, Louisiana State University, Baton Rouge, LA.

Ripple, W. J. 1986. Spectral reflectance relationships to leaf water stress, Photogramm. Eng. Remote Sens. 52(10):1669-1775.

SPSS. 1999. Systat Users Guide. SPSS Inc., Chicago, IL.

Takahashi, H., C. S. Brown, T. W. Dreschel, and T. K. Scott. 1992. Hydrotropism in Pea Roots in a Porous
Tube-Water Delivery System. HortScience 27(5):430432.

Tsao, D., M. R. Okos, J. C. Sager, and T. W. Dreschel. 1992. Development of Physical and Mathematical Models for the Porous Ceramic Tube Plant Nutrification System (PCTPNS). NASA Technical Memorandum \# 107551, The National Aeronautics and Space

Administration, J. F. Kennedy Space Center, Florida.

Tsao, D. T. W., M. R. Okos, and J. C. Sager. 1996. Controlling the Water Availability from a Ceramic Tube System Subjected to Non-Standard Gravities. Mimeo. Paper \#961505 presented to the $26^{\text {th }}$ International Conference on Environmental Systems, The Society of Automotive Engineers, Monterey, CA.

Tucker, C. J. 1980. Remote sensing of leaf water content in the near infrared. Remote Sens. Environ. 10:23-32.

\section{CONTACT}

Thomas W. Dreschel, Ph.D.

KSC Biological Sciences Office

Mail Code: YA-E4

Kennedy Space Center, FL 32899

Phone: (321) 867-2926

Pager: (321) 232-7667

Fax: (321) $867-4234$

thomas.w.dreschel@nasa.gov

http://weboflife.nasa.gov

\section{DEFINITIONS, ACRONYMS, ABBREVIATIONS}

LED Light Emitting Diodes, currently under evaluation as a plant lighting system for space exploration applications

PTPNDS Porous Tube Plant Nutrient Delivery System, a hydroponic plant growth system that delivers water and nutrients to the roots of plants by capillary action in a controlled fashion. 